\title{
Downregulation of pyrophosphate: D-fructose-6-phosphate 1-phosphotransferase activity in sugarcane culms enhances sucrose accumulation due to elevated hexose-phosphate levels
}

\author{
Margaretha J. van der Merwe • \\ Jan-Hendrik Groenewald • Mark Stitt • \\ Jens Kossmann · Frederik C. Botha
}

Received: 1 September 2009/ Accepted: 9 November 2009/Published online: 2 December 2009

(C) The Author(s) 2009. This article is published with open access at Springerlink.com

\begin{abstract}
Analyses of transgenic sugarcane clones with 45-95\% reduced cytosolic pyrophosphate: D-fructose-6phosphate 1-phosphotransferase (PFP, EC 2.7.1.90) activity displayed no visual phenotypical change, but significant changes were evident in in vivo metabolite levels and fluxes during internode development. In three independent transgenic lines, sucrose concentrations increased between three- and sixfold in immature internodes, compared to the levels in the wildtype control. There was an eightfold increase in the hexose-phosphate:triose-phosphate ratio in immature internodes, a significant restriction in the triose phosphate to hexose phosphate cycle and significant increase in sucrose cycling as monitored by ${ }^{13} \mathrm{C}$ nuclear magnetic resonance. This suggests that an increase in the hexose-phosphate concentrations resulting from a restriction in the conversion of hexose phosphates to triose
\end{abstract}

Electronic supplementary material The online version of this article (doi:10.1007/s00425-009-1069-1) contains supplementary material, which is available to authorized users.

M. J. van der Merwe $(\bowtie) \cdot$ J.-H. Groenewald · J. Kossmann · F. C. Botha

Institute of Plant Biotechnology, University of Stellenbosch,

Merriman Avenue, Stellenbosch 7602, South Africa

e-mail: mvdm@sun.ac.za

Present Address:

J.-H. Groenewald

PlantBio, Postnet Suite 201, P/Bag X6,

Cascades 3202, South Africa

F. C. Botha

SRDC, PO Box 12050, George Street,

Brisbane, QLD 4003, Australia

M. Stitt

Max Planck Institute of Molecular Plant Physiology,

Am Muehlenberg 1, Golm 14476, Germany phosphates drive sucrose synthesis in the young internodes. These effects became less pronounced as the tissue matured. Decreased expression of PFP also resulted in an increase of the ATP/ADP and UTP/UDP ratios, and an increase of the total uridine nucleotide and, at a later stage, the total adenine nucleotide pool, revealing strong interactions between PPi metabolism and general energy metabolism. Finally, decreased PFP leads to a reduction of PPi levels in older internodes indicating that in these developmental stages PFP acts in the gluconeogenic direction. The lowered PPi levels might also contribute to the absence of increases in sucrose contents in the more mature tissues of transgenic sugarcane with reduced PFP activity.

Keywords Metabolite profiling - PFP - Substrate cycle . Sucrose $\cdot$ Sugarcane

$\begin{array}{ll}\text { Abbreviations } \\ \text { ADP } & \text { Adenosine 5'-diphosphate } \\ \text { AI } & \text { Acid invertase } \\ \text { AMP } & \text { Adenosine 5'-monophosphate } \\ \text { ATP } & \text { Adenosine 5'-triphosphate } \\ \text { CWI } & \text { Cell wall invertase } \\ \text { DHAP } & \text { Dihydroxyacetone phosphate } \\ \text { FBPase } & \text { Fructose-1,6-bisphosphatase } \\ \text { F1,6P } & \text { Fructose-1,6-bisphosphate } \\ \text { F2,6P } & \text { Fructose-2,6-bisphosphate } \\ \text { FK } & \text { Fructokinase } \\ \text { F6P } & \text { Fructose-6-phosphate } \\ \text { F6P 2K } & \text { Fructose-6-phosphate 2-kinase } \\ \text { GC MS } & \text { Gas chromatography mass spectrometry } \\ \text { G1P } & \text { Glucose-1-phosphate } \\ \text { G6P } & \text { Glucose-6-phosphate }\end{array}$




$\begin{array}{ll}\text { HK } & \text { Hexokinase } \\ \text { HPLC } & \text { High-pressure liquid chromatography } \\ \text { NI } & \text { Neutral invertase } \\ \text { NMR } & \text { Nuclear magnetic resonance } \\ \text { PFK } & \text { Phosphofructokinase } \\ \text { PFP } & \begin{array}{l}\text { Pyrophosphate: D-fructose-6-phosphate } \\ \end{array} \\ \text { 1-phosphotransferase } \\ \text { 3-PGA } & \text { Glyceraldehyde-3-phosphate } \\ \text { PPi } & \text { Pyrophosphate } \\ \text { SPS } & \text { Sucrose phosphate synthase } \\ \text { SUSY } & \text { Sucrose synthase } \\ \text { UDP } & \text { Uridine 5'-diphosphate } \\ \text { UDPGlc } & \text { UDP glucose } \\ \text { UGPase } & \text { UDPGlc pyrophosphorylase } \\ \text { UMP } & \text { Uridine 5'-monophosphate } \\ \text { UTP } & \text { Uridine 5'-triphosphate } \\ \text { V-PPase } & \text { Vacuolar pyrophosphatase }\end{array}$

\section{Introduction}

In most plants, sucrose is the main form in which organic carbon is translocated from source to sink tissues. In sugarcane (Saccharum sp. hybrids), the internodal sinks have the ability to accumulate approximately $12-16 \%$ of sucrose on a fresh mass basis in the mature organs (Bull and Glasziou 1963). Estimates reveal, however, that this value is far from exceeding the maximum capacity of the sugarcane culm (Moore et al. 1997; Grof and Campbell 2001). Therefore, increasing the sucrose yield has been a key objective in several sugarcane improvement programmes.

PFP catalyzes a reversible reaction between fructose 6-phosphate $(\mathrm{F} 6 \mathrm{P})$ and pyrophosphate $(\mathrm{PPi})$ to fructose 1,6-bisphosphate $\left(\mathrm{F} 1,6 \mathrm{P}_{2}\right)$ and inorganic phosphate $(\mathrm{Pi})$ (Carnal and Black 1979). This enzyme occurs simultaneously with the canonical glycolytic enzyme ATPdependent phosphofructokinase (PFK, EC 2.7.1.11) and the gluconeogenic enzyme fructose-1,6-bisphosphatase (FBPase), and is regulated by the signal metabolite fructose-2,6-bisphosphate $\left(\mathrm{F} 2,6 \mathrm{P}_{2}\right)$ (Stitt 1990). This is a unique feature in plant metabolism. It is linked to another unusual feature of plant metabolism, which is that PPi is used in parallel with ATP as an energy donor in the cytoplasm of plant cells. PPi is generated in many reactions required for cellular growth, including the synthesis of polysaccharides, RNA and amino acid activation and is typically hydrolyzed to render these reactions irreversible. However, while plastids contain high pyrophosphatase activity and negligible $\mathrm{PPi}$, the cytosol of plants cells contains a significant pool of PPi (Weiner et al. 1987;
Stitt 1998). This PPi can be used in various reactions including PFP, sucrose synthase (SUSY; Stitt 1998) and a tonoplast bound pyrophosphatase (Baltscheffsky et al. 1999; Maeshima 2000). These reactions offer an alternative to an ATP-dependent reaction sequence. In Arabidopsis, five cytosolic-targeted soluble pyrophosphatases have been reported (Du Jardin et al. 1995); however, pyrophosphatase activity in the cytosol is very low compared to that in the plastid (Weiner et al. 1987) and is presumably regulated to allow the maintenance of significant PPi levels.

Despite intensive research, the precise role of PFP remains enigmatic. Although numerous studies have provided indirect and correlative evidence for a role of PFP in glycolysis, gluconeogenesis or catalysis of a metabolite cycle between hexose phosphates and triose phosphates (Stitt 1990), downregulation of PFP in transgenic potato tubers (Hajirezaei et al. 1994) and tobacco leaves (Paul et al. 1995; Nielsen and Stitt 2001) did not lead to major effects in plant growth, respiration and/or sucrose or starch pools. This indicates that PFP does not play an essential role in carbon metabolism in these plant species. In sugarcane, a negative correlation was found between PFP activity and sucrose levels in the maturing sugarcane culm (Whittaker and Botha 1999). This correlative evidence indicates that PFP may play a regulatory role in carbon partitioning toward the sugarcane sucrose pool. Further, we previously reported that transgenic sugarcane clones with reduced cytosolic pyrophosphate: D-fructose-6-phosphate 1-phosphotransferase (PFP, EC 2.7.1.90) activity has a 50\% increase in sucrose levels in immature internodal tissue (Groenewald and Botha 2001, 2008). However, the mechanism behind this increase remains unclear.

One hypothesis that could explain this increase is that, during maturation in sugarcane, sucrose accumulation is characterized by a shift of carbon partitioning away from respiration and/or the insoluble matter (Whittaker and Botha 1997). As the central metabolite pool involved in these biosynthetic processes, the hexose phosphate pool might play a vital role in governing sucrose accumulation. Together with PFK, PFP forms the first committed step toward respiration (Theodorou and Plaxton 1996). Enhanced hexose phosphate levels might enhance substrate availability and drive sucrose synthesis directly. Many plant tissues show a rapid cycle of sucrose synthesis and degradation, which will sensitive the net flux to sucrose to small changes in either of these unidirectional fluxes, Sucrose synthase catalyses a reversible reaction (Geigenberger and Stitt 1993), and sucrose phosphate synthase (SPS) is allosterically activated by glucose 6-phosphate (Doehlert and Huber 1983, 1984) through the inhibitory capacity of glucose 6-phosphate on protein 
phosphatase 2A (PP2A) proteins (MacKintosh et al. 1990; Siegl et al. 1990). Hexose phosphates could also exert their effect through signaling dependent processes. For example, hexose kinases might sense and regulate sugar levels (Jang and Sheen 1994) as well as hexose phosphates have been shown to modulate the substrate cycles they are involved in (Roby et al. 2002). Sucrose accumulation in sugarcane is also marked by a continuous cycle of synthesis and degradation (Whittaker and Botha 1997), even within maturing internodes (Sacher et al. 1963; Wendler et al. 1990; Whittaker and Botha 1997). A significant proportion of this carbon is recycled by either triose-phosphate:hexosephosphate and/or sucrose cycles (Sacher et al. 1963; Batta and Singh 1986; Wendler et al. 1990; Whittaker and Botha 1997; Bindon and Botha 2000). Triose-phosphate:hexosephosphate cycling is high in immature tissue of sugarcane, returning approximately $50 \%$ of carbon from the triosephosphate pool to the hexose-phosphate pool. With the onset of maturation, there is a marked reduction in triosephosphate:hexose-phosphate cycling (Bindon and Botha 2002) and cycling within the sucrose pool also decrease twofold with maturation (Whittaker and Botha 1997). These substrate cycles are postulated to control sucrose accumulation in vivo (Whittaker and Botha 1997; Rohwer and Botha 2001).

We now report a detailed examination of the biochemical and metabolic consequences of a perturbation in PFP activity. First, the prevailing hexose phosphate levels, as well as a wide range of metabolite were determined by GC MS, enzymatic-coupled assays and HPLC analyses. Second, flux distributions were determined from ${ }^{13} \mathrm{C}$ NMR analyses.

\section{Materials and methods}

\section{Plant material}

Clones of Saccharum spp. hybrid variety NCo310 (South African Sugarcane Research Institute, Mt Edgecombe, South Africa) with varying degrees of reduced PFP $\beta$ expression (Groenewald and Botha 2001) were grown in a courtyard in Stellenbosch, South Africa. Culms with approximately 14 aboveground internodes were randomly selected and were harvested in the summer months. Internodal tissue selected for analysis was excised from the stalk and the rind carefully removed. The first internode from which the leaf with the first exposed dewlap originates was defined as internode one (Van Dillewijn 1952).

The underlying tissue, spanning the core to the periphery, was rapidly sliced, homogenized and frozen in liquid nitrogen within $1 \mathrm{~h}$ after harvesting. Stalks from four individual plants were used as replicates.
Biochemicals

All auxiliary enzymes, cofactors and substrates used for enzyme assays and metabolite determinations were purchased from either Sigma-Aldrich Fluka (SAF) Chemical Company (St. Louis, MO, USA) or Roche Diagnostics (Basel, Switzerland), unless stated otherwise.

Enzyme extraction and measurement

Protein content expressed on a cell basis does not differ between internodes (Bindon and Botha 2000) and protein content per internode and total cell number remains stable in sugarcane (Botha et al. 1996). All results for metabolite and enzyme activity determinations are therefore compared on a soluble protein basis to compensate for changes in the volume of the cytosolic compartment during development.

\section{Protein extraction}

The extraction procedure for the measurement of PFP activity was carried out at $4{ }^{\circ} \mathrm{C}$ according to the method of Lingle and Smith (1991). Crude extracts were prepared by homogenization of internodal tissue in liquid nitrogen. The ground tissue was suspended in ice-cold extraction buffer in a buffer volume to tissue mass of 2:1 and was continuously stirred for $15 \mathrm{~min}$. The standard extraction buffer contained $100 \mathrm{mM}$ Tris-Cl (pH 7.2), $2 \mathrm{mM} \mathrm{MgCl}, 2 \mathrm{mM}$ EDTA, $5 \mathrm{mM}$ DTT, $2 \%(\mathrm{~m} / \mathrm{v})$ PVPP and $10 \%$ (v/v) glycerol. Extracts were centrifuged for $5 \min \left(4^{\circ} \mathrm{C}\right)$ at $10,000 \mathrm{~g}$ and the supernatants retained.

\section{Protein determination}

The protein content was measured according to the method of Bradford (1976) using bovine serum albumin (BSA) as a standard.

Enzyme activity measurements

PFP activity was measured in the glycolytic direction according to Kruger et al. (1983). The standard reaction mixture contained $100 \mathrm{mM}$ Tris-Cl $(\mathrm{pH} 7.5), 1 \mathrm{mM}$ $\mathrm{MgCl}_{2}, 10 \mathrm{mM}$ F6P, $0.1 \mathrm{mM}$ NADH, $10 \mu \mathrm{M}$ F2,6P $2,1 \mathrm{U}$ aldolase, $10 \mathrm{U}$ triose-phosphate isomerase and $1 \mathrm{U}$ glycerol-3-P dehydrogenase. Activity was initiated by the addition of $1 \mathrm{mM}$ PPi. NADH oxidation at $340 \mathrm{~nm}$ was followed on a Beckman DU ${ }^{\circledR} 7500$ spectrometer (Beckman Coulter Inc., Fullerton, CA, USA) to quantify PFP activity. The pH optima of neutral invertase (NI) and acid invertase (AI) were previously determined (Hatch et al. 1963). Assay conditions were previously described and followed exactly (Huber and Akazawa 1986). SPS activity was determined 
by a modified method from Huber (1983). The assay mixture for SPS activity measurements contained in a final volume of $50 \mu \mathrm{l}$ a concentration of $100 \mathrm{mM}$ Tris ( $\mathrm{pH} 7.5$ ), $10 \mathrm{mM} \mathrm{MgCl} 2,0.2 \mathrm{mM} \mathrm{NaF}, 2 \mathrm{mM}$ F6P, $10 \mathrm{mM}$ G6P and $25 \mathrm{mM}$ UDP-glucose. Initiation of the reaction was achieved by the enzyme extract, and the reaction terminated after incubation for $1 \mathrm{~h}$ by addition of $70 \mu \mathrm{l} 30 \%$ (m/ v) $\mathrm{KOH}$. Tubes were immersed in boiling water for $10 \mathrm{~min}$, cooled and incubated in a mixture of $0.14 \%$ anthrone in $80 \% \mathrm{H}_{2} \mathrm{SO}_{4}$ for $20 \mathrm{~min}$ at $40^{\circ} \mathrm{C}$. The activity of the protein product was determined spectrophotometrically at $620 \mathrm{~nm}$ by comparison of a linear calibration curve for glucose. SUSY (hydrolysis direction) was assayed as described by Huber and Akazawa (1986) with $320 \mathrm{mM}$ sucrose and $1.5 \mathrm{mM}$ UDP as substrates. Hexokinase (HK) and fructokinase (FK) activities were determined spectrophotometrically at $340 \mathrm{~nm}$ exactly as described by Hoepfner and Botha (2003). Phosphofructokinase (PFK) activity was quantified according to the protocol of Gibon et al. (2004) using the cycling enzyme based protocol.

\section{Metabolite determination}

\section{GC MS analyses}

To analyze the levels of primary metabolites a GC quadropole MS protocol for plant material (Roessner et al. 2000) was optimized for sugarcane tissue (Bosch et al. 2003). $\pm 100 \mathrm{mg}$ homogenized internodal tissue stored at $-80^{\circ} \mathrm{C}$ were extracted with $430 \mu \mathrm{l} 100 \%$ pre-chilled methanol, $30 \mu \mathrm{l} 20 \mathrm{mM}$ Na-Hepes (pH 8.5) containing $2 \mathrm{mM}$ EDTA and $150 \mu \mathrm{l} 100 \%$ chloroform with $10 \mu \mathrm{l}$ $3.94 \mu \mathrm{g}^{-1}$ ribitol (in Hepes buffer) as internal standard. The mixture was incubated for $10 \mathrm{~min}$ at $28^{\circ} \mathrm{C}$, centrifuged for $15 \mathrm{~min}$ at $4,000 \mathrm{~g}$ and the supernatant transferred to clean tubes. Supernatant $(100 \mu \mathrm{l})$ were dried down in a rotary evaporator, RT. The dried residue was subsequently redissolved and derivatized for $90 \mathrm{~min}$ at $30^{\circ} \mathrm{C}$ in $80 \mu \mathrm{l}$ $30 \mathrm{mg} \mathrm{ml}^{-1}$ methoxyamine hydrochloride (in pyridin). Samples were trimethylsilylated by a $30 \mathrm{~min}$ treatment at $37^{\circ} \mathrm{C}$ containing $140 \mu \mathrm{l}$ MSTFA. $n$-Alkane retention time standard mixture was also added prior to trimethylsilylation. Samples were injected splitless into a GC quadropole MS (ThermoFinnigan Ltd., Herts, Hertfordshire, UK) and run according to specifications of Roessner et al. (2001). The GC was mounted with a 5PDM VF- $5 \mathrm{~ms}, 0.25 \mu \mathrm{m}$ film thickness, $30 \mathrm{~m}$ by $0.25 \mathrm{~mm}$ fused silica capillary column (Varian, Darmstadt, Germany), which had an integrated $10 \mathrm{~m}$ guard column. The injector temperature was $230^{\circ} \mathrm{C}$ and helium carrier gas used at a constant flow of $1 \mathrm{ml} \mathrm{min}{ }^{-1}$. The temperature program consisted of an initial $1 \mathrm{~min}$ isothermal period at $70^{\circ} \mathrm{C}$ and a $7.7^{\circ} \mathrm{C} \mathrm{min}{ }^{-1}$ ramp to $310^{\circ} \mathrm{C}$. Mass spectral recording was set to 20 scans $\mathrm{s}^{-1}$. The transfer line and ion source temperatures were set to $250^{\circ} \mathrm{C}$. The monitored mass range was $\mathrm{m} / \mathrm{z} 70$ 600. Peak integration was done by means of the ICIS algorithm in Xcalibur (ThermoFinnigan) and metabolite levels were quantified by the establishment of linear calibration curves as described by Roessner et al. (2000).

\section{Enzyme coupled metabolite determinations}

Metabolite determinations via spectrometry were extracted according to Whittaker and Botha (1997). Samples dried down under vacuum were resuspended in deionised distilled $\mathrm{H}_{2} \mathrm{O}$. The following metabolites were measured spectrophotometrically at $340 \mathrm{~nm}$, using a Beckman DU ${ }^{\circledR}$ 7500 spectrophotometer (Beckman Coulter Inc.). PEP and pyruvate (Czok and Lambrecht 1974); DHAP, G3P and F1,6P 2 (Michal and Beutler 1974), sucrose, glucose and fructose (Bergmeyer and Bernt 1974); G6P, F6P (Lang and Michal 1974) and G1P, F2,6P (Scott and Kruger 1994), as well as PPi and Pi (Bergmeyer and Bernt 1974; Drueckes et al. 1995). G6P, F6P and G1P were measured by the consecutive addition of $0.1 \mathrm{U}$ 6-phosphogluconase, $0.1 \mathrm{U}$ hexose phosphate isomerase and $0.1 \mathrm{U}$ phosphoglucomutase to the standard reaction mixture (Lang and Michal 1974). The amount of $F 2,6 P_{2}$ was measured through the stimulation of potato tuber PFP. The assay buffer contained $25 \mathrm{mM}$ Tris-acetate ( $\mathrm{pH} 7.8), 2 \mathrm{mM} \mathrm{Mg-acetate,} 1 \mathrm{mM}$ F6P (acid treated to remove traces of $\mathrm{F} 2,6 \mathrm{P}_{2}$ ), $0.24 \mathrm{mM}$ NADH, 0.1 U aldolase, 1.6 U TPi, 4.5 U GDH and $2.7 \mathrm{mU}$ potato PFP. The PFP reaction was initiated by the addition of $0.4 \mathrm{mM}$ PPi in an assay volume of $230 \mu \mathrm{l}$. After $3 \mathrm{~min}$, in the plate reader, a volume of $20 \mu \mathrm{l}$ containing the metabolite extracts $(2 \mu \mathrm{l})$ or internal standards was added. The internal standards refer to metabolite extracts from which the endogenous $\mathrm{F} 2,6 \mathrm{P}_{2}$ content was hydrolyzed by the addition of 0.1 volumes of $2 \mathrm{M} \mathrm{HCl}$, followed by a 15 min incubation period, RT. The extracts were then neutralized by the addition of an equal volume of $2 \mathrm{M}$ $\mathrm{NaOH}$. The solution were kept on ice for $2 \mathrm{~min}$, followed by the addition of $10 \mathrm{mM}$ Tris-acetate $(\mathrm{pH} 7.8)$ to insure that the extracts contained the same amount of pre-mixed ions. The extracts were spiked with authentic F2,6 $\mathrm{P}_{2}(0.05$ and 1 pmol) standards for linear calibration quantification of $\mathrm{F} 2,6 \mathrm{P}_{2}$ for each sample. PPi and Pi concentration was determined colorimetrically with the addition of $2.4 \mathrm{U}$ inorganic pyrophosphatase and $0.02 \mathrm{M} \mathrm{MgCl}_{2}$ solution to the standard reaction mixture. The standard reaction mixture contained $40 \mu \mathrm{l}$ ammonium molybdate reagent (15 $\mathrm{mM}$ zinc acetate and $10 \mathrm{mM}$ ammonium molybdate (pH 5.0) and $160 \mu \mathrm{l}$ reducing agent [10\% ascorbic acid ( $\mathrm{pH}$ 5.0)]. Pi and PPi concentration in sugarcane internodal tissue were calculated by comparing authentic standards from a linear curve to the absorbance measured at $660 \mathrm{~nm}$ 
at $34^{\circ} \mathrm{C}$. Coupling factors were desalted prior to use in the enzymatic assays by centrifugation at $10,000 \mathrm{~g}, 4^{\circ} \mathrm{C}$, and reconstituting in sterile $\mathrm{H}_{2} \mathrm{O}$.

\section{HPLC analyses}

TCA/ether extracted nucleotides and nucleotide sugars (Jelitto et al. 1992) were filtered through Millex-GV4 $(0.22 \mu \mathrm{m})$ units (Millipore, Billerica, MA, USA) prior to injection onto a high-performance liquid chromatography (HPLC; Shimadzu Co., Kyoto, Japan) system. Adenylates (ATP, ADP, and AMP) and uridinylates (UTP, UDP, UDP glucose) were separated in extracts $(10 \mu \mathrm{l}$ injection volume) by HPLC on a 150 by $4.6 \mathrm{~mm}$ Phenomenex Aqua $(5 \mu \mathrm{m}) \mathrm{C} 18$ 125A column (Phenomenex,Torrance, CA, USA) according to a modified method of Viola et al. (1994). Nucleotides were detected by their absorbance at $254 \mathrm{~nm}$ and identified by co-chromatography with authentic nucleotide standards. The quantity of each nucleotide and nucleotide sugar was determined by comparing the sample peak areas to those of the corresponding standard. Mobile phases constituted of (A) $0.1 \mathrm{M} \mathrm{KH}_{2} \mathrm{PO}_{4} /$ $\mathrm{K}_{2} \mathrm{HPO}_{4}$ and $5 \mathrm{mM}$ tetrabutylammonium hydrogen sulphate (pH 6.0) and (B) $70 \% \mathrm{~A}$ and $30 \%$ methanol. The linear flow gradient employed was $0.9 \mathrm{ml} \mathrm{min}^{-1}$ for $\mathrm{A}$ and $0 \mathrm{ml} \mathrm{min}{ }^{-1}$ for $\mathrm{B}$ for the first $10 \mathrm{~min}$, after which the gradient was changed to $0.8 \mathrm{ml} \mathrm{min}^{-1}$ (A) and $0.5 \mathrm{ml} \mathrm{min}^{-1}$ (B). After $20 \mathrm{~min}$, the program was set to gradually refer back to the original flow rates. The column temperature was maintained at $30^{\circ} \mathrm{C}$ throughout.

\section{NMR analyses}

\section{$\left[{ }^{13} C\right]$-labeling experiments}

Tissue discs ( $1 \mathrm{~mm}$ thickness) were washed after excision four times in distilled deionised water. Excess liquid was removed by blotting and tissue discs [20 per sealed $100 \mathrm{ml}$ Erlenmeyer flask containing $650 \mu \mathrm{l}$ incubation buffer (50 mM MES, pH 6.5, $50 \mathrm{mM} 99.9 \%$ enriched $1-{ }^{13} \mathrm{C}$ glucose and $50 \mathrm{mM}$ fructose)] were incubated for $6 \mathrm{~h}$ with constant shaking $(150 \mathrm{rpm})$ on a rotary shaker at $28^{\circ} \mathrm{C}$. Sampling was done by removal of 10 tissue discs after $3 \mathrm{~h}$ and $6 \mathrm{~h}$, respectively, for sugar and label incorporation determinations. After labeling, tissue were rinsed and washed for five times in wash buffer (50 mM MES, pH6.5). Excess buffer was removed and soluble sugars extracted.

\section{Sugar extractions}

Sugars were extracted as previously described (Bindon and Botha 2002). The tissue discs were soaked at $70^{\circ} \mathrm{C}$, overnight in $70 \%(\mathrm{v} / \mathrm{v})$ ethanol and $30 \%$ (v/v) HM buffer [100 mM HEPES (pH 7.8), $20 \mathrm{mM} \mathrm{MgCl}_{2}$ ]. The discs were crushed and incubated for a further $2 \mathrm{~h}$. Extracts were centrifuged at room temperature for $10 \mathrm{~min}$ at $10,000 \mathrm{~g}$ and the supernatant collected. The supernatants were filtered through PVDF $0.45 \mu \mathrm{m}$ filters (Millipore) and the filtrates loaded onto preconditioned (bed weight $100 \mathrm{mg}$, volume $1 \mathrm{ml}$ ) ion exchange (IEX) columns (LC-SCX and LCSAX; Supelco Inc., Bellefonte, CA, USA). The IEX columns were placed in tandem (LC-SCX tube on top) for solid phase extraction according to the manufacturer's recommendations. Samples were eluted with $4 \mathrm{ml} \mathrm{ddH_{2 }} \mathrm{O}$. Complete elution of the neutral fraction was achieved by washing the anion exchange columns four times with $1 \mathrm{ml}$ $\mathrm{ddH}_{2} \mathrm{O}$ and combining all the eluate fractions. The collected neutral fraction were dried down under vacuum, redissolved in deuterium oxide $\left(\mathrm{D}_{2} \mathrm{O}\right)$ to a final amount of $20 \mathrm{mg} \mathrm{g}^{-1}$ fresh mass and subjected to NMR analyses.

\section{NMR running conditions}

NMR spectra were recorded on a $600 \mathrm{MHz}{ }^{\text {Unity Inova }}$ spectrometer (Varian) equipped with an Oxford magnet (14.09T; Oxford Instruments, Abingdon, Oxfordshire, UK). A standard pulse sequence was used for collecting ${ }^{13} \mathrm{C}$ spectra at a frequency of $150 \mathrm{MHz}$. An acquisition time of $1.3 \mathrm{~s}$ and a $1 \mathrm{~s}$ pulse delay were used with a pulse angle of $43 \mathrm{deg}$. Number of scans varied from 5,500 to 65,500 depending on the sample. Chemical shifts were normalized relative to the field lock of $\mathrm{D}_{2} \mathrm{O}$. Reference spectra for sucrose, fructose and glucose were collected under the same conditions and compared to resonance assignment and integration for glucose, fructose and sucrose spectra as previously described (Viola et al. 1991; Krook et al. 2000a, b). Peak areas at 104.29 ppm (sucrosefructosyl C2), $98.68 \mathrm{ppm}$ ( $\beta$ fructose $\mathrm{C} 2-5) 96.53 \mathrm{ppm}(\beta$ glucose C1), 92.78 ppm (sucrose-glucosyl C1), 81.97 ppm (sucrose-fructosyl C5), $81.30 \mathrm{ppm} \mathrm{(} \beta$ fructose C2-5), $77.03 \mathrm{ppm}$ (sucrose-fructosyl C3), $76.57 \mathrm{ppm}$ ( $\beta$ glucose C5), $76.40 \mathrm{ppm}$ ( $\beta$ glucose $\mathrm{C} 3$ ), $76.04 \mathrm{ppm}$ ( $\beta$ fructose $\mathrm{C} 2$ 5), $75.08 \mathrm{ppm}$ ( $\beta$ fructose $\mathrm{C} 2-5), 74.76 \mathrm{ppm}(\beta$ glucose C2), $\quad 74.61 \mathrm{ppm}$ (sucrose-fructosyl C4), $73.18 \mathrm{ppm}$ (sucrose-glucosyl C3), 73.01 ppm (sucrose-glucosyl C5), $71.67 \mathrm{ppm}$ (sucrose-glucosyl C4), $70.77 \mathrm{ppm}$ ( $\beta$ fructose C2-5), $70.22 \mathrm{ppm}$ ( $\beta$ glucose $\mathrm{C} 4), 69.81 \mathrm{ppm}(\beta$ fructose $\mathrm{C} 2-5), \quad 68.20 \mathrm{ppm}(\beta$ fructose $\mathrm{C} 2-5), 64.52 \mathrm{ppm}(\beta$ fructopyranose $\mathrm{C} 1), 63.99 \mathrm{ppm}$ ( $\beta$ fructopyranose $\mathrm{C} 6$ ), $63.33 \mathrm{ppm}$ ( $\beta$ fructofuranose $\mathrm{C} 1$ ), $62.96 \mathrm{ppm}$ (sucrosefructosyl C6), $61.97 \mathrm{ppm} \quad$ (sucrose-fructosyl C1), 61.38 ppm ( $\beta$ glucose C6) and 60.73 ppm (sucrose-glucosyl C6) were integrated. Initially, both anomers were considered during spectra analysis. Due to a low detection signal from the $\alpha$ anomer for fructose and glucose, only the 
$\beta$ anomer was considered for the further quantification of the sugars.

\section{Statistical analyses}

Students $t$ tests (two-tailed) were performed on the Microsoft ${ }^{\circledR}$ Excel software package (Microsoft Corporation Inc., Seattle, WA, USA). The term significant is used to indicate differences for which $P<0.05$.

\section{Results}

Evaluation of PFP activity in internodal tissue of transgenic sugarcane lines

The expression profile of PFP in a series of previously generated transgenic clones (Groenewald and Botha 2001) (designated OPu50_) was determined in order to select internodes representing material with reduced PFP protein activity. Of these clones, the four representing a significant reduction in PFP expression in intermodal tissue 3, 6 and 9, namely OPu501, OPu505, OPu506 and OPu508 were selected for further biochemical analyses (Table 1). These transgenic lines displayed between 45 and $95 \%$ reduction in PFP activity (Table 1). They displayed no phenotypical change in regards to culm morphology (data not shown).

Evaluation of enzyme activities involved in sucrose metabolism in transgenic sugarcane clones with reduced PFP activity

Following the confirmation that the sugarcane clones expressed less PFP protein product compared to the control, enzyme activities of the most prevalent proteins within sucrose metabolism were evaluated during the three developmental stages defined earlier (Figs. 1, 2, 3, 4). This

Table 1 Characterization of PFP enzyme activity in the sugarcane culm of internodes 3, 6 and 9 in wildtype (interspecific hybrid $\mathrm{NCo} 310$ ) and four independent transgenic lines (OPu501, OPu505, OPu506 and OPu508) with reduced PFP activity

\begin{tabular}{lccc}
\hline Genotype & Internode 3 & Internode 6 & Internode 9 \\
\hline PFP activity & $\left(\mathrm{nmol} \mathrm{min}^{-1} \mathrm{mg}^{-1}\right.$ & protein $)$ & \\
WT & $84.315 \pm 7.150$ & $7.769 \pm 0.223$ & $5.508 \pm 0.337$ \\
OPu501 & $\mathbf{2 5 . 5 9 2} \pm \mathbf{0 . 8 9 9}$ & $\mathbf{4 . 4 4 8} \pm \mathbf{0 . 1 9 0}$ & $\mathbf{1 . 5 4 9} \pm \mathbf{0 . 0 6 0}$ \\
OPu505 & $\mathbf{1 . 0 7 9} \pm \mathbf{0 . 0 4 6}$ & $\mathbf{0 . 0 8 1} \pm \mathbf{0 . 0 0 5}$ & $\mathbf{0 . 0 5 0} \pm \mathbf{0 . 0 0 2}$ \\
OPu506 & $\mathbf{1 . 1 7 6} \pm \mathbf{0 . 0 4 5}$ & $\mathbf{0 . 1 9 4} \pm \mathbf{0 . 0 0 9}$ & $\mathbf{0 . 0 5 9} \pm \mathbf{0 . 0 0 4}$ \\
OPu508 & $\mathbf{2 . 4 4 3} \pm \mathbf{0 . 1 0 9}$ & $\mathbf{0 . 1 1 6} \pm \mathbf{0 . 0 0 7}$ & $\mathbf{0 . 0 6 1} \pm \mathbf{0 . 0 0 2}$
\end{tabular}

Values are presented as mean \pm SE of four individual plants per line; values set in bold type were determined by the $t$ test to be significantly different $(P<0.05)$ from the respective wildtype (WT) internode indicated little significant changes in PFK activity (Fig. 4a). It should be noted (compare Fig. 4a and Table 1) that in wildtype plants PFP activity is $>10$-fold higher than PFK activity in internode 3 , but in internode 6 and 9 falls to levels that are similar to PFK.

In addition, the maximal catalytic activities of sucrose phosphate synthase (SPS), acid invertase (AI), neutral invertase (NI) and sucrose synthase (SUSY) assayed for hydrolysis of sucrose (Fig. 4b-d, g) remained invariable from the respective WT internodes. Furthermore, despite little consistency during the early developmental stage, hexokinase (HK) and fructokinase (FK) activity were significantly decreased in the more maturing (i.e. internode 6 and 9) internodes (Fig. 4e, f) in the transgenic lines as compared to the untransformed controls.

Evaluation of the primary metabolome in down-regulated PFP transgenic lines

We used GC MS to investigate changes in the primary metabolome of transgenic lines with reduced PFP activity. Due to the difficulties with obtaining reproducible recoveries during GC MS analyses (Supplemental Table 1), phosphorylated intermediates and the soluble sugars, sucrose, glucose and fructose, were quantified either through HPLC or spectrophotometric methods.

The results indicated a significant increase in the hexose-phosphate pool (G6P, F6P, G1P) and UDP glucose in the transgenic lines (Fig. 4). There was also a significant decrease in $\mathrm{F} 1,6 \mathrm{P}_{2}$ levels and triose-phosphate pool (DHAP and 3PGA) in the young internode of all the transgenic clones (Fig. 4). This indicates that net conversion of hexose phosphates to downstream glycolytic metabolites has been restricted. In addition, F2,6 $\mathrm{P}_{2}$ levels decreased significantly in the immature internodes (Fig. 4). This was unexpected as $\mathrm{F} 2,6 \mathrm{P}_{2}$ is an activator of PFP, and was reported to increase in previous studies of transgenic material with decreased expression of PFP (Hajirezaei et al. 1994; Paul et al. 1995; Nielsen and Stitt 2001).

Most of the differences between wildtype plants and the PFP transgenic lines become smaller or are abolished as internodes mature (Fig. 4). Similarly, sucrose, glucose and fructose contents are significantly elevated in internode 3 but seem to revert to those of the control values during maturation (Fig. 4). The exception to this is the level of fructose that is still elevated in internode 9 compared to the wildtype (Fig. 4).

In order to evaluate if the enhanced level of sucrose was due to enhanced hexose phosphate levels and not due to pleiotropic effects arising from altering pyrophosphate (PPi) metabolism, we measured PPi and other energy constituents across the three developmental stages (Fig. 4). PPi levels were unaffected or showed a non-significant 
Fig. 1 Generalized pathway diagram of sucrose metabolism in the sugarcane sink. Sucrose accumulation during maturation in the culm is characterized by a decrease in two substrate cycles, namely triose phosphate hexose phosphate- and sucrose cycling. The common intermediate in these two cycles, the hexose phosphate pool (fructose-6-P, glucose-6-P, glucose-1-P and UDP-glucose) also serves as substrate for, among others, sucrose synthesis. PFP may contribute to the status of the hexose phosphate pool in sink tissue by regulating the carbon flux between sucrose

accumulation and respiration. Due to negligible FBPase activity reported in sugarcane internodes, it also appears that only PFP can regulate gluconeogenic carbon flux in sugarcane sink metabolism (adapted from Krook et al. 2000a)

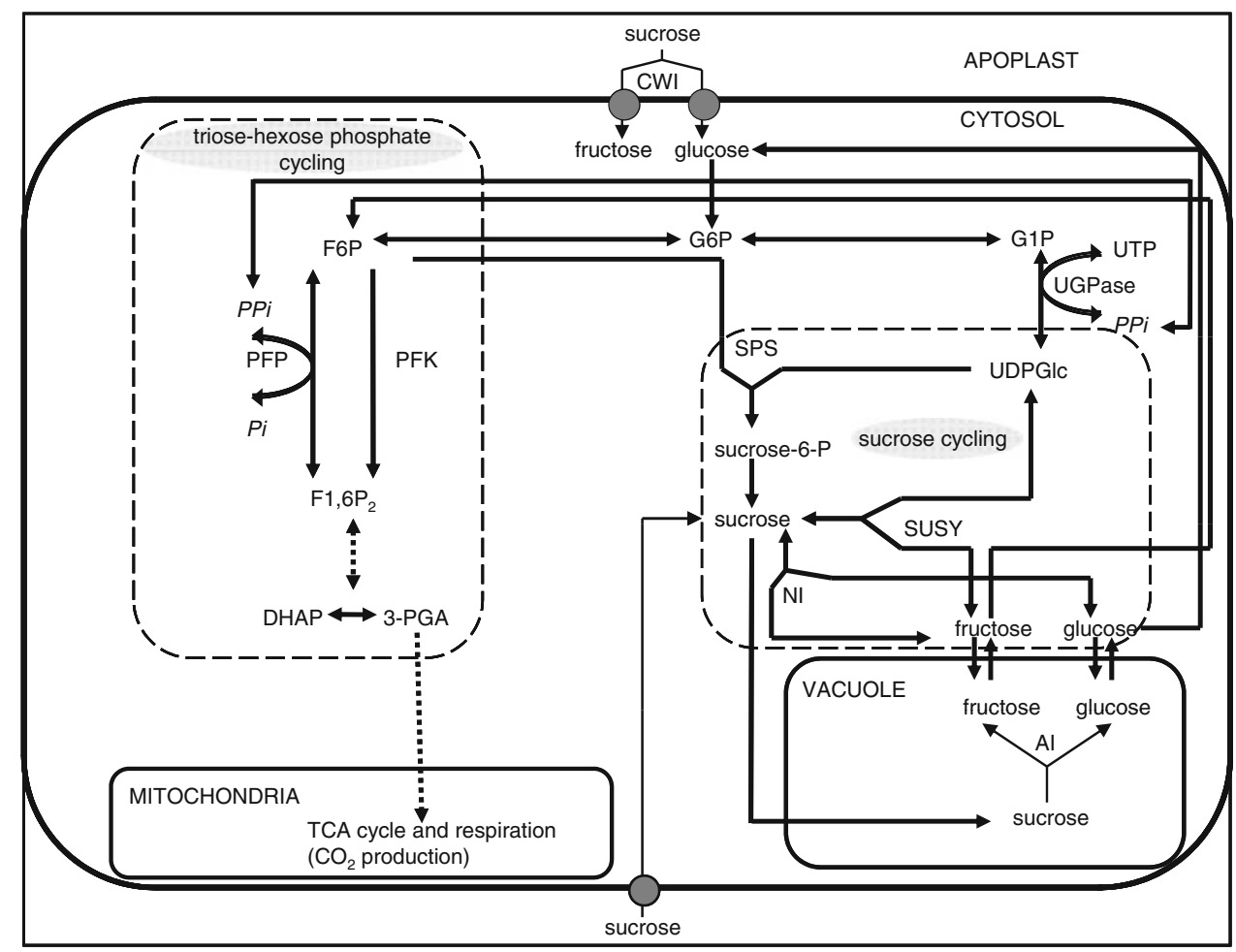

upwards trend in the young intermodal tissue, but significantly reduced in older internodes in the lines with decreased expression of PFP (Fig. 4). ATP remained unaltered while ADP and AMP were significantly reduced in the young internodes (Fig. 4), which results in an increase in the ATP/ADP ratio and energy change. With maturation of the internodes, ATP was also elevated in the lines with reduced PFP activity, and there was a marked increase in the size of the total adenine nucleotide pool (ATP + ADP + AMP) (Fig. 4).

There was also a strong increase of UTP and decrease of UDP in the transgenic lines in young internodes, resulting in a sixteen-fold increase of the UTP/UDP ratio (Fig. 4). In older internodes, the transgenic lines showed an increase of UTP and UDP (Fig. 4). Comparison with Fig. 4 reveals that the total uridine nucleotide pool (UTP + UDP + UDPGlc) was increased by 2- to 7-fold in the transgenic lines. Further, there was a very large (up to 10-fold) decrease in the UDPGlc:UDP ratio in the transgenic lines at all stages of development. Most of the uridine nucleotide pool (UDPGlc + UTP + UDP) is located in the cytoplasm. Most of this pool is present as UDPGlc, and UTP and UDP are equilibrated with ATP and ADP via uridine diphosphate kinase (Dancer et al. 1990).

Evaluation of the other primary metabolites indicated that the succinate levels decreased across the transgenic lines and with maturation (Table 2). A similar pattern was observed for 2-oxoglutarate and quinate (Table 2). In contrast, the levels of aconitate increased significantly
(Table 2), while the remaining organic acids exhibited variable levels between genotypes and also across developmental stages (Table 2). In contrast, the other sugars profiled appeared in general to decrease within the independent transgenic lines (Supplemental Table 1). These included the levels of ribose, inositol, maltose and trehalose (Supplemental Table 1). Total amino acid concentration, on the other hand, increased in general in the transgenic lines (Supplemental Table 1). The exceptions to this included the concentrations of valine, glycine and especially glutamine in the immature internodes of the transgenic sugarcane clones (Supplemental Table 1). Large significant increases in alanine, glycine, isoleucine, serine threonine and valine were also evident in internode 6 during the maturation process (Supplemental Table 1).

In addition to the evaluation of the steady state metabolite levels, the dynamic fluxes of two substrate cycles involved in glycolysis in sugarcane was investigated by supplying $\left[1-{ }^{13} \mathrm{C}\right]$-glucose to wildtype and the OPu506 transgenic lines in young (internode 3 and 4 ) and maturing (internode 6 and 7) internodes (Table 3). In regards to this, positional label incorporation determined by ${ }^{13} \mathrm{C} N \mathrm{NMR}$ after a $6 \mathrm{~h}$ incubation period indicated little enrichment in position $\mathrm{C} 3$ in any of the soluble sugars, suggesting that the cyclic flux through the non-oxidative pentose phosphate pathway was negligible in sugarcane internodal tissue (data not shown). Sucrose cycling, as calculated by the flux of total label $\left({ }^{13} \mathrm{C}\right.$ in both the glucosyl and fructosyl moiety) recovered in the sucrose pool from $1-{ }^{13} \mathrm{C}$ glucose 




Fig. 2 Characterization of enzyme activities in sugarcane intermodal tissue involved in sucrose metabolism. Maximal catalytic activity for a sucrose phosphate synthase (SPS), b phosphofructokinase (PFK), c acid invertase (AI), d neutral invertase (NI), e hexokinase (HK), $\mathbf{f}$ fructokinase (FK) and $\mathbf{g}$ sucrose synthase [(hydrolysis) SUSY (hydrolysis)] were determined in wildtype (filled circle), OPu501

incubations and the return of total ${ }^{13} \mathrm{C}$ label $(\mathrm{C} 1+\mathrm{C} 6)$ into fructose over the $6 \mathrm{~h}$ incubation time, and relative to the endogenous sugar concentration, revealed a similar rate of sucrose cycling at both stages of development in wildtype internodes. In contrast, in the OPu506 immature internodes $(3+4)$ a 9-fold increase in both sucrose hydrolysis and synthesis was observed, while in the maturing internodes

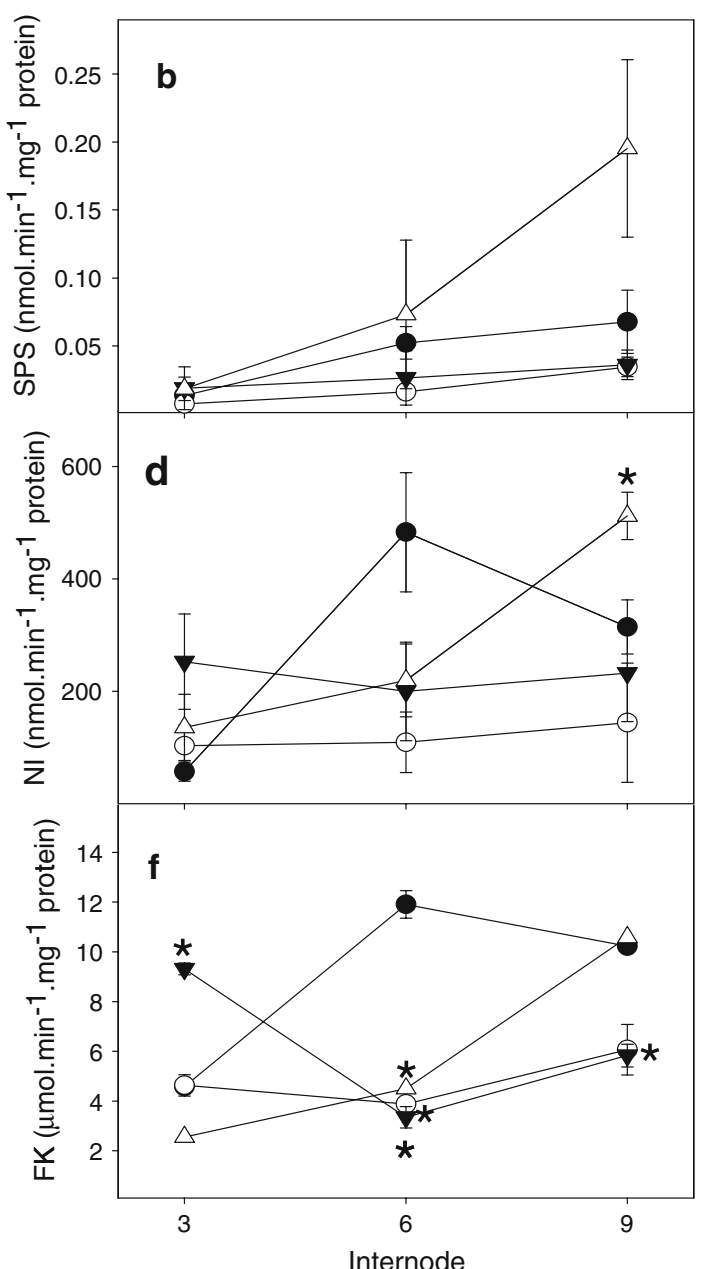

(open circle), OPu506 (filled inverted triangle) and OPu508 (open triangle). Values are presented as mean \pm SE of four individual plants per line; an asterisk (*) indicates a value that were determined by the $t$ test to be significantly different $(P<0.05)$ from the respective wildtype (WT) internode

$(6+7)$ a 3 - and 1.8 -fold increase was observed for sucrose hydrolysis and synthesis, respectively (Table 3). Furthermore, determining the triose phosphate to hexose phosphate recycling from exchange of label from position $\mathrm{C} 1-$ C6 in the fructosyl moiety, and taking into account the phosphorylation rate and cytosolic contribution of exogenous applied glucose (Malone et al. 2006), indicated a 


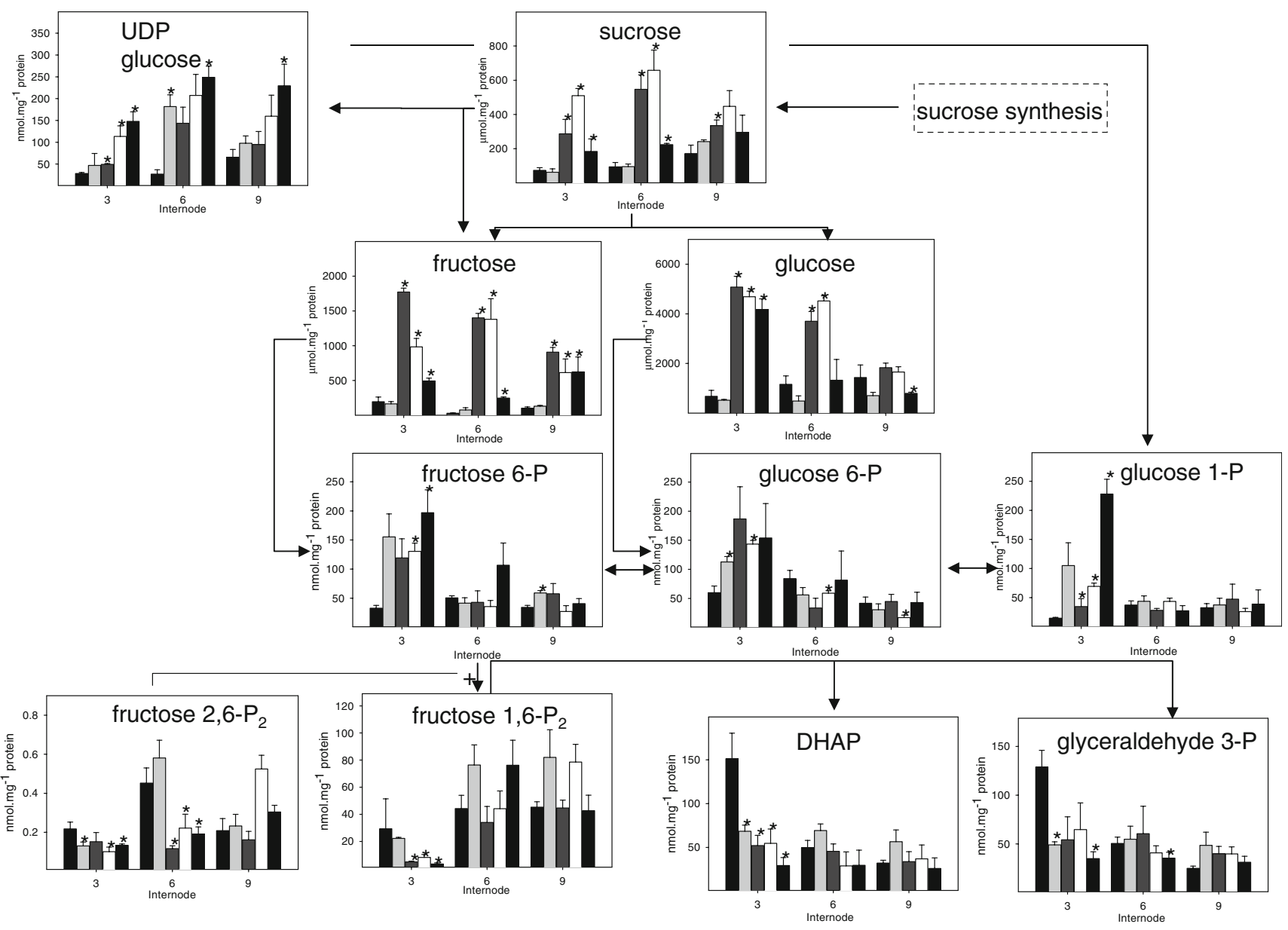

Fig. 3 Effect of decreased PFP activity on glycolytic intermediates down-stream of sucrose catabolism. Soluble sugars, hexose phosphate and triose phosphate content was quantified in intermodal tissue 3, 6 and 9 of wildtype (black bar), OPu501 (light gray bar), OPu505 (gray bar), OPu506 (white bar) and OPu508 (dark gray bar). Data are

significant reduction in triose phosphate to hexose phosphate recycling in the immature (stage $3+4$ ) transgenic internodes, but not in older internodes (Table 3). Due to the destructive method used for these experiments, care should, however, be taken into the interpretation of the absolute amounts of these fluxes as reported in Table 3.

\section{Discussion}

Sugarcane, a complex poly-aneuploid, is traditionally cultivated for its ability to accumulate high sucrose levels. Despite intense research efforts, the attainable goal of increasing sucrose yield has not been reached to date. In our laboratory, preliminary results (Groenewald and Botha 2008) showed that PFP in the sugarcane culm, curiously, enhance sucrose accumulation especially in the younger internodes. However, the mechanism, until now, remained unknown.

representative of the mean $\pm \mathrm{SE}$ on four individual plants per line. An asterisk (*) indicates a value that were determined by the $t$ test to be significantly different $(P<0.05)$ from the respective wildtype (WT) internode

Here, it was shown that decreased expression of PFP inhibits triose phosphate to hexose phosphate recycling, and concomitantly increases hexose phosphate pools in the immature internodes. Cycling between triose phosphates and hexose phosphates is probably due to the reversible reaction catalyzed by PFP (Stitt 1990). The decrease in cycling in transgenic lines with decreased expression of PFP provides evidence that the in vivo activity of PFP has indeed been decreased. The increase of hexose phosphate levels and decrease of downstream metabolites like DHAP, glyceraldehyde 3-P and $\mathrm{F} 1,6 \mathrm{P}_{2}$ provides independent evidence that the net flux catalyzed by PFP is in the direction of triose phosphate formation, and that this net flux has been decreased.

The increase in the levels of hexose phosphates provides one explanation for enhanced sucrose levels in immature internodes. Another contributory factor could be the overall increase of the uridine nucleotide pool, especially the large increase of UDPGlc and decrease of UDP. Increased 


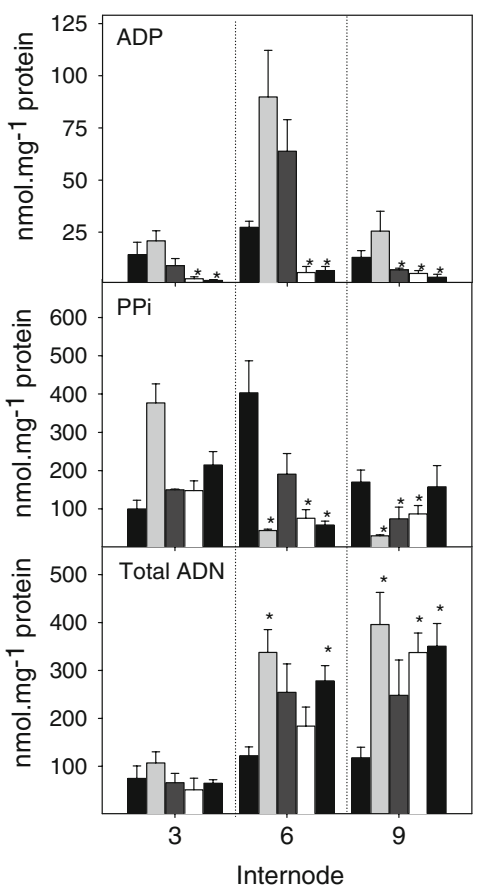

Fig. 4 Energy intermediates of sugarcane intermodal tissue 3, 6 and 9 from wildtype (black bar) and downregulated PFP transgenic lines (OPu501, light gray bar; OPu505, gray bar; OPu506, white bar; OPu508, dark gray bar). Adenylate (ADP, AMP, ATP), pyrophosphate (PPi), uridinylates (UDP and UTP), and total adenylate (total $\mathrm{ADN} ; \mathrm{ATP}+\mathrm{ADP}+\mathrm{AMP}$ ) and uridinylate (total UDN;
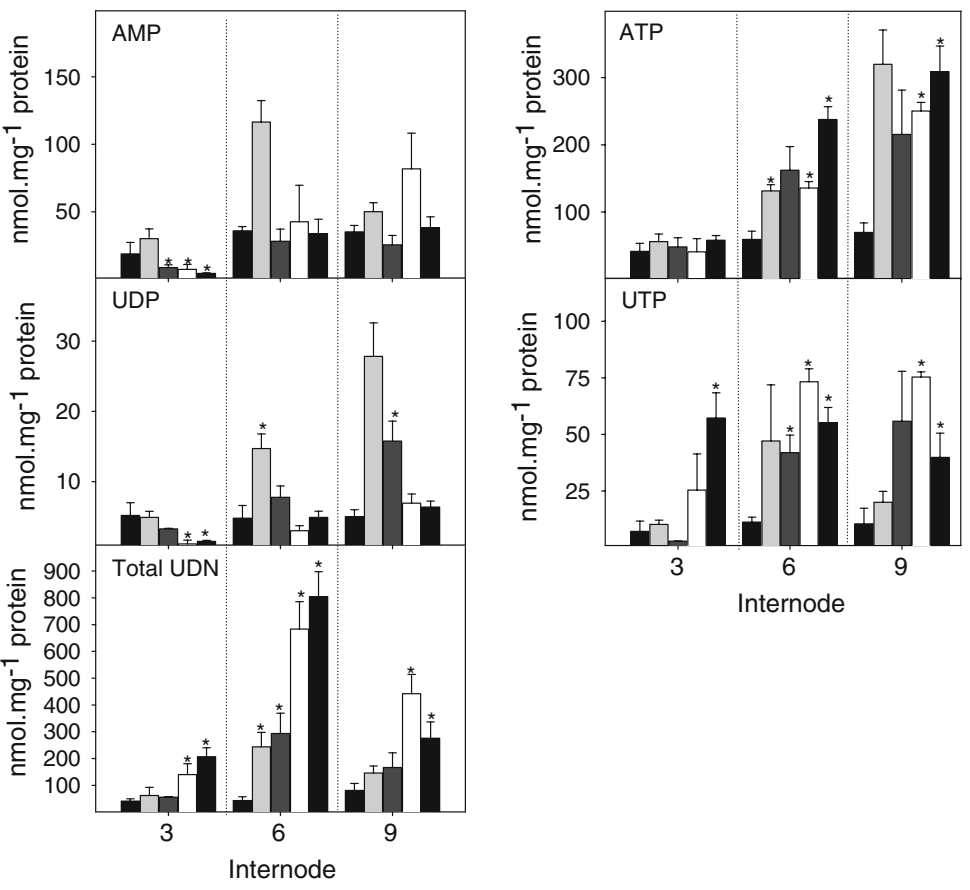

UTP + UDP + UDP glucose) levels are depicted. Data are representative of the mean $\pm \mathrm{SE}$ on four individual plants per line; an asterisk (*) indicates a value that were determined by the $t$ test to be significantly different $(P<0.05)$ from the respective wildtype (WT) internode

Table 2 Organic acid levels of sugarcane internodes 3, 6 and 9 from antisense PFP (OPu_50) lines determined by GC MS technology (nmol $\mathrm{mg}^{-1}$ protein)

\begin{tabular}{llclcccc}
\hline Genotype_int & Succinate & \multicolumn{1}{l}{ Malate } & 2-Oxoglutarate & Aconitate & Shikimate & Citrate & Quinate \\
\hline WT_3 & 60.27 \pm 6.63 & $582.87 \pm 6.41$ & $41.98 \pm 6.30$ & $935.46 \pm 10.29$ & $77.89 \pm 8.57$ & $60.83 \pm 6.69$ & $174.05 \pm 19.15$ \\
OPu501_3 & $\mathbf{2 5 . 5 6} \pm \mathbf{2 . 8 1}$ & $1227.98 \pm 15.84$ & $50.05 \pm 5.51$ & $\mathbf{1 , 3 9 9 . 9 6} \pm \mathbf{4 2 . 0 0}$ & $282.30 \pm 64.93$ & $60.93 \pm 6.70$ & $657.89 \pm 7.47$ \\
OPu505_3 & ND & $\mathbf{3 1 8 . 0 6} \pm \mathbf{3 . 5 0}$ & $\mathbf{2 4 . 8 7} \pm \mathbf{2 . 7 4}$ & $\mathbf{6 , 0 2 5 . 0 4} \pm \mathbf{6 6 . 2 8}$ & $\mathbf{3 3 . 7 3} \pm \mathbf{3 . 7 1}$ & $84.79 \pm 9.33$ & $\mathbf{2 8 . 3 5} \pm \mathbf{3 . 1 2}$ \\
OPu506_3 & $\mathbf{0 . 9 3} \pm \mathbf{0 . 1 0}$ & $552.45 \pm 6.08$ & $\mathbf{1 1 . 3 3} \pm \mathbf{1 . 2 5}$ & $\mathbf{7 , 4 7 5 . 3 0} \pm \mathbf{8 2 . 2 3}$ & $42.48 \pm 4.67$ & $\mathbf{3 0 . 6 3} \pm \mathbf{3 . 3 7}$ & $\mathbf{8 3 . 8 8} \pm \mathbf{9 . 2 3}$ \\
OPu508_3 & ND & $\mathbf{3 1 4 . 7 7} \pm \mathbf{3 . 4 6}$ & $\mathbf{3 . 3 4} \pm \mathbf{0 . 3 7}$ & $\mathbf{5 , 5 1 6 . 6 9} \pm \mathbf{6 0 . 6 8}$ & $\mathbf{3 3 . 3 3} \pm \mathbf{3 . 6 7}$ & $\mathbf{1 8 . 6 8} \pm \mathbf{2 . 0 5}$ & ND \\
WT_6 & $101.68 \pm 11.18$ & $465.41 \pm 5.12$ & $25.78 \pm 2.84$ & $222.19 \pm 2.44$ & $133.04 \pm 14.63$ & $139.57 \pm 15.35$ & $162.73 \pm 17.90$ \\
OPu501_6 & $\mathbf{3 0 . 3 5} \pm \mathbf{3 . 3 4}$ & $\mathbf{8 2 5 . 4 7} \pm \mathbf{9 . 0 8}$ & $\mathbf{4 7 . 6 6} \pm \mathbf{5 . 2 4}$ & $269.76 \pm 2.97$ & $152.41 \pm 16.76$ & $137.60 \pm 15.14$ & $124.06 \pm 13.65$ \\
OPu505_6 & $\mathbf{2 . 9 3} \pm \mathbf{0 . 3 2}$ & $349.53 \pm 3.84$ & $25.20 \pm 2.77$ & $\mathbf{1 3 , 7 2 2 . 7 6} \pm \mathbf{1 5 . 1 0}$ & $90.66 \pm 9.97$ & $165.52 \pm 18.21$ & $\mathbf{1 1 9 . 0 8} \pm \mathbf{1 3 . 1 0}$ \\
OPu506_6 & $\mathbf{2 . 7 0} \pm \mathbf{0 . 3 0}$ & $403.69 \pm 4.44$ & $\mathbf{1 4 . 8 9} \pm \mathbf{1 . 6 4}$ & $\mathbf{4 , 1 7 4 . 6 0} \pm \mathbf{4 5 . 9 2}$ & $\mathbf{3 0 . 0 7} \pm \mathbf{3 . 3 1}$ & $\mathbf{3 0 . 6 9} \pm \mathbf{3 . 3 8}$ & $\mathbf{4 1 . 0 7} \pm \mathbf{4 . 5 2}$ \\
OPu508_6 & $\mathbf{1 . 3 5} \pm \mathbf{0 . 1 5}$ & $505.06 \pm 5.56$ & $\mathbf{1 4 . 0 9} \pm \mathbf{1 . 5 5}$ & $\mathbf{1 , 7 7 0 . 7 3} \pm \mathbf{1 9 . 4 8}$ & $\mathbf{2 1 . 5 3} \pm \mathbf{2 . 3 7}$ & $\mathbf{5 6 . 3 3} \pm \mathbf{6 . 2 0}$ & $\mathbf{4 1 . 7 3} \pm \mathbf{4 . 5 9}$ \\
WT_9 & $2.83 \pm 3.11$ & $175.62 \pm 1.93$ & ND & $599.74 \pm 6.60$ & $7.27 \pm 0.80$ & $60.61 \pm 6.67$ & $4.08 \pm 0.45$ \\
OPu501_9 & $\mathbf{8 . 4 4} \pm \mathbf{9 . 2 8}$ & $\mathbf{1 , 3 4 0 . 6 9} \pm \mathbf{1 4 . 7 5}$ & $\mathbf{2 8 . 6 7} \pm \mathbf{3 . 1 5}$ & $483.46 \pm 5.32$ & $\mathbf{6 8 . 4 6} \pm \mathbf{7 . 5 3}$ & $\mathbf{1 2 2 . 6 9} \pm \mathbf{1 3 . 5 0}$ & $\mathbf{3 1 . 6 8} \pm \mathbf{3 . 4 8}$ \\
OPu505_9 & $2.38 \pm 2.62$ & $216.36 \pm 2.38$ & $\mathbf{1 1 . 6 8} \pm \mathbf{1 . 2 8}$ & $\mathbf{4 , 3 1 6 . 4 3} \pm \mathbf{4 7 . 4 8}$ & $\mathbf{3 8 . 4 8} \pm \mathbf{4 . 2 3}$ & $\mathbf{9 8 . 7 8} \pm \mathbf{1 0 . 8 7}$ & $\mathbf{2 1 . 4 8} \pm \mathbf{2 . 3 6}$ \\
Opu506_9 & $\mathbf{1 . 1 8} \pm \mathbf{1 . 3 0}$ & $350.00 \pm 3.85$ & $\mathbf{7 . 9 5} \pm \mathbf{0 . 8 7}$ & $\mathbf{2 , 4 7 5 . 7 9} \pm \mathbf{2 7 . 2 3}$ & $\mathbf{4 8 . 7 4} \pm \mathbf{5 . 3 6}$ & $51.36 \pm 5.65$ & $\mathbf{1 2 . 1 9} \pm \mathbf{1 . 3 4}$ \\
OPu508_9 & $\mathbf{0 . 8 8} \pm \mathbf{0 . 9 7}$ & $238.53 \pm 2.62$ & $\mathbf{5 . 5 3} \pm \mathbf{0 . 6 1}$ & $465.72 \pm 5.12$ & $8.64 \pm 0.95$ & $61.97 \pm 6.82$ & $3.72 \pm 0.41$ \\
\hline
\end{tabular}

Values are presented as mean \pm SE of four individual plants per line and values in bold type were determined by the $t$ test to be significantly different $(P<0.05)$ from the respective wildtype (WT) internode (int). $N D$ denotes a value that was below detection limit

hexose phosphates and UDPGlc may allow allosteric activation of SPS; in maize and spinach leaves and potato tubers, sucrose phosphate synthase (SPS) activity has been shown to be allosterically activated by G6P or UDPGlc (Amir and Preiss 1982; Doehlert and Huber 1983; KaltTorres et al. 1987; Reimholz et al. 1994). UDP and 
Table 3 Substrate cycles in sugarcane immature (internode 3 and 4) and maturing (internode 6 and 7) internodes to evaluate sucrose cycling (flux into sucrose from $1-{ }^{13} \mathrm{C}$ glucose and flux toward fructose from sucrose relative to pool size; $\mathrm{mmol} \mathrm{min}^{-1} \mathrm{mg}^{-1}$ protein) and triose phosphate:hexose-phosphate cycling (arbitrary units) after a $6 \mathrm{~h}$ incubation time $\left(\mathrm{mmol} \mathrm{min}^{-1} \mathrm{mg}^{-1}\right.$ protein)

\begin{tabular}{lcll}
\hline & Flux into fructose from sucrose & Flux from $1-{ }^{13} \mathrm{C}$ glucose into sucrose & Triose-P to hexose-P recycling $\left(\frac{v T \rightarrow H}{v H K \varphi}\right)$ \\
\hline WT & & & $4.37 \pm 0.70$ \\
Internode $3+4$ & $9.98 \pm 0.85$ & $100.43 \pm 14.56$ & $1.52 \pm 0.13$ \\
Internode $6+7$ & $13.40 \pm 1.56$ & $254.87 \pm 13.22$ & $\mathbf{0 . 9 0} \pm \mathbf{0 . 4 2}$ \\
OPu506 & & & $1.68 \pm 1.28$ \\
Internode $3+4$ & $\mathbf{9 0 . 1 2} \pm \mathbf{9 . 5 6}$ & $\mathbf{9 0 1 . 3 3} \pm \mathbf{8 8 . 9 9}$ & $\mathbf{4 5 6 . 1 1} \pm \mathbf{5 0 . 8 7}$ \\
Internode $6+7$ & $\mathbf{4 2 . 3 0} \pm \mathbf{5 . 6 7}$ &
\end{tabular}

Internodal discs were incubated in $50 \mathrm{mM}\left[1{ }^{13} \mathrm{C}\right]$ glucose $(99.9 \%$ enrichment) and $50 \mathrm{mM}$ unlabeled fructose prior to sugar extractions and determination of label incorporation by NMR spectroscopy. The triose phosphate to hexose phosphate recycling $(\nu T \rightarrow H)$ was determined as described by Fernie et al. (2001) taking into account the relative rate of external glucose metabolised to phosphorylated cytosolic glucose ( $v H K$ ) and the proportion of the cytosolic glucose pool drawn from exogenous labeled glucose $(\varphi)$ as defined in Malone et al. (2006). Values are presented as mean \pm SE of three individual plants per line; bold indicates a value that were determined by the $t$-test to be significantly different $(P<0.05)$ from the respective wildtype (WT) internode

UDPGlc are also reactants in the essentially reversible reaction (Geigenberger and Stitt 1993) catalyzed by SUSY. The massive decrease of the UDP and increase of UDPGlc may decrease sucrose degradation and increase sucrose synthesis via SUSY in transgenic lines with decreased PFP. It will also increase the sucrose and decrease the fructose concentration at which this reaction reaches equilibrium.

Flux measurements showed that transgenics with decreased expression of PFP have a rapid cycle of sucrose synthesis and degradation, with higher rates of sucrose synthesis and higher rates of sucrose degradation than in wildtype plants. This is consistent with the hypothesis that the level of sucrose is set by the balance between synthesis and degradation. Increased pools of hexose phosphates and UDPGlc allow higher rates of sucrose synthesis, resulting in an increase in the concentration of sucrose and increased rates of degradation. The steady state content of sucrose will be reached when the rising rate of degradation matches the rate of synthesis.

With maturation, both sucrose and hexose phosphate levels, as well as triose phosphate to hexose phosphate recycling, appear to be restored to those of the wildtype control. While the direct effect of enhanced substrate availability leading to increased sucrose levels had not been shown to date, it has been suggested previously to be a mechanism to explain enhanced sucrose levels in antisense PFP transgenic lines (Groenewald and Botha 2008). Furthermore, other metabolite changes that were prevalent in the PFP transgenic lines were the predominance of a reduction in diverse sugar levels, as well as the organic acids succinate and quinate, and a general increase in amino acids and the levels of aconitate (Table 2, Supplemental Table 1). However, these observations were independent from the restoration with maturation, and suggest that these effects were not correlated with the enhanced sucrose content. The transgenic immature internodes were also characterized by decreased levels of 2-oxoglutarate (Table 2) and glutamine (Supplemental Table 1) suggesting that $\mathrm{N}$ assimilation might be compromised in the PFP transgenic lines at this development stage.

The cytosol of plants cells contains a significant pool of PPi and low pyrophosphatase activity (Weiner et al. 1987; Stitt 1998) that can be used in various reactions including PFP, SUSY and a tonoplast bound pyrophosphatase (Baltscheffsky et al. 1999; Maeshima 2000). In each case, these reactions offer an alternative to an ATP-dependent reaction sequence. In transgenic plants with decreased PFP, PPi levels showed a weak and non-significant upwards trend in young internodes, and a significant decrease in older internodes. This decrease is consistent with PFP catalyzing a net gluconeogenic (PPi-generating) flux in older internodes. This reversed response in mature internodes might be explained by the change in the relative activities of PFP and PFK; PFP activity decreases almost 10 -fold and is now of the same order as PFK. In this situation, the main glycolytic flux may be catalyzed by PFK, and PFP may catalyze a net conversion of triose phosphates to hexose phosphate. In agreement, the hexose phosphate:triose phosphate ratio in older internodes is similar in the transgenic lines and the wildtype control. This illustrates the flexibility of PFP and PPi metabolism in plants.

Another striking response to low PFP expression was that there was an increase of the total uridine nucleotide pool (see above) and the UTP/UDP and ATP/ADP ratios. This illustrates the close connectivity between PPi metabolism and nucleotide energy metabolism. However, it is not known precisely why the phosphorylation potential and the nucleotide pools increase when PFP activity is decreased. With maturation, there was a decrease in PPi levels, the changes of the uridine nucleotide pool, the UTP/UDP and ATP/ADP 
ratios were maintained, and there was also an increase in the overall levels of adenylates (Fig. 4). This switch in energy metabolism suggests that either alternative PPi competing pathways, such as the afore-mentioned vacuolar-associated pyrophosphatase (V-PPase) might be utilizing PPi or that PFP might operate in a gluconeogenic direction in maturing internodes. Neither of these explanations is without precedence since interspecific hybrids with different abilities to accumulate sucrose show a linear relationship with endogenous V-PPase activity (Swart 2005). In addition, under abiotic stress conditions, where osmoticum play a key role, it has been shown that PFP re-directs carbon in a gluconeogenic direction (Mustroph et al. 2005; Kovács et al. 2006).

Despite large alterations in the steady state metabolite levels and dynamic fluxes of sucrose cycles, the corresponding enzyme activities associated directly with sucrose synthesis and hydrolysis show a poor correlation with sucrose maximas (Fig. 4). This discrepancy in maximal enzyme activity and metabolite fluxes suggest that allosteric and posttranslational mechanisms are governing in vivo enzyme activities. In maize and spinach leaves and potato tubers, sucrose phosphate synthase (SPS) activity has been shown to be activated by G6P levels (Amir and Preiss 1982; Doehlert and Huber 1983; Kalt-Torres et al. 1987; Reimholz et al. 1994). In sugarcane, the downregulation of neutral invertase (NI) in cell suspension cultures also led to enhanced sucrose levels that diminished with maturation (Rossouw et al. 2007) suggesting a sensitivity of the system to prevailing sucrose levels. Sugarcane leaves which have been cold-girdled results in increased sucrose, glucose and fructose levels while photosynthesis is also impaired (McCormick et al. 2008). Possible role players in this sugar-sensing mechanism has been identified as involved in trehalose metabolism while PFP expression was also significantly reduced $(\sim 40 \%)$ (McCormick et al. 2008), suggesting that the mechanism(s) that govern the regulation of the phosphorylated sugar pool is a likely target for engineering sugarcane that is less sensitive to prevailing sugar content.

Finally, F2,6 $\mathrm{P}_{2}$ levels decreased significantly in the immature internodes of transgenic plants with decreased activity of PFP (Fig. 4). F2,6 $\mathrm{P}_{2}$, an activator of PFP, was reported to increase in previous studies of transgenic material with decreased expression of PFP (Hajirezaei et al. 1994; Paul et al. 1995; Nielsen and Stitt 2001). Further, based on work on enzymes from spinach leaves and carrot tubers, increased F6P would be expected to stimulate fructose-6phosphate 2-kinase (F6P, 2K) and inhibit F2,6BPase (Stitt 1990) leading to an increase of $\mathrm{F} 2,6 \mathrm{P}_{2}$. It has been proposed in earlier studies of transgenic material with decreased expression of PFP that the increase of $\mathrm{F} 2,6 \mathrm{P}_{2}$ would compensate for decreased expression of PFP. The absence of a similar increase in sugarcane immature internodes might explain why decreased expression of PFP has a more marked impact on metabolism than in other tissues studied previously. This also suggests that $\mathrm{F} 2,6 \mathrm{P}_{2}$ levels are regulated by other mechanisms in sugarcane internodes. The possibility of phosphorylation of F6P, $2 \mathrm{~K}$, catalyzing the synthesis of $\mathrm{F} 2,6 \mathrm{P}_{2}$, has been suggested by the binding of F6P, $2 \mathrm{~K}$ to phosphopeptide binding sites on 14-3-3 proteins (Kulma et al. 2004) and provides one plausible explanation to this effect. In light of the results obtained here, the characterization and regulation of endogenous $\mathrm{F} 2,6 \mathrm{P}_{2}$ levels in sugarcane remains an exciting topic for future research.

In conclusion, despite the role of PFP in different crop species under unstressed conditions remaining unresolved, in sugarcane it has a definitive role and effect on carbohydrate partitioning. This suggests that PFP (and its regulatory components) is differently regulated in a sucrose driven storage organ in comparison with other plant species and/or plant organs studied thus far.

Acknowledgments We are thankful for financial support by the South African Sugar Research Institute, Department of Trade and Industry and the National Research Foundation. Also sincere thanks to James Lloyd (Institute for Plant Biotechnology, University of Stellenbosch) for helpful discussions and comments on the paper and Jean McKenzie (Department Chemistry, University of Stellenbosch) who conducted the NMR analyses.

Open Access This article is distributed under the terms of the Creative Commons Attribution Noncommercial License which permits any noncommercial use, distribution, and reproduction in any medium, provided the original author(s) and source are credited.

\section{References}

Amir J, Preiss J (1982) Kinetic characterization of spinach leaf sucrose-phosphate synthase. Plant Physiol 69:1027-1030

Baltscheffsky M, Schultz A, Baltscheffsky H (1999) $\mathrm{H}^{+}$-PPases: a tightly membrane-bound family. FEBS Lett 457:527-533

Batta SK, Singh R (1986) Sucrose metabolism in sugar cane grown under varying climatic conditions: synthesis and storage of sucrose in relation of the activities of sucrose synthase, sucrosephosphate synthase and invertase. Phytochem 25:2431-2437

Bergmeyer HU, Bernt E (1974) Sucrose. In: Bergmeyer HU (ed) Methods of enzymatic analysis, 2nd edn. Academic Press, Verlag Chemie, Weinheim, pp 1176-1179

Bindon K, Botha FC (2000) Tissue discs as an experimental system for metabolic flux analysis in sugarcane culm. S Afr J Bot 66:260-264

Bindon KA, Botha FC (2002) Carbon allocation to the insoluble fraction, respiration and triose-phosphate cycling in the sugarcane culm. Physiol Plant 116:12-19

Bosch S, Rohwer JM, Botha FC (2003) The sugarcane metabolome. Proc S Afr Sug Technol Ass 7:129-133

Botha FC, Whittaker A, Vorster DJ, Black KG (1996) Sucrose accumulation rate, carbon partitioning and expression of key enzyme activities in the sugarcane culm. In: Wilson JR, Hogarth DM, Campbell JA, Garside AL (eds) Sugarcane: research towards efficient sustainable production. CSIRO division of Tropical Crops and Pastures, Brisbane, pp 98-101 
Bradford MM (1976) A rapid sensitive method for the quantification of microgram quantities of protein utilizing the principle of protein-dye binding. Anal Biochem 72:248-254

Bull TA, Glasziou KT (1963) The evolutionary significance of sugar accumulation in Saccharum. Aust J Biol Sci 16:737-742

Carnal NW, Black CC (1979) Pyrophosphate-dependent phosphofructokinase, a new glycolytic enzyme in pineapple leaves. Biochem Biophys Res Commun 86:20-26

Czok L, Lambrecht W (1974) Pyruvate, phosphoenolpyruvate and Dglycerate-2-phosphate. In: Bergmeyer HU (ed) Methods in enzymatic analysis, 3rd edn. Academic Press, New York, pp 1446-1451

Dancer JE, Neuhaus HE, Stitt M (1990) The subcellular compartmentation of uridine nucleotides and nucleoside-5-diphosphate kinase in leaves. Plant Physiol 92:637-641

Doehlert DC, Huber SC (1983) Regulation of spinach leaf sucrose phosphate synthase by glucose-6-phosphate, inorganic phosphate, and pH. Plant Physiol 73:989-994

Doehlert DC, Huber SC (1984) Phosphate inhibition of spinach leaf sucrose-phosphate synthase as affected by glucose-6-phosphate and phosphoglucoisomerase. Plant Physiol 76:250-253

Drueckes P, Schinzel R, Palm D (1995) Photometric microtiter assay of inorganic phosphate in the presence of acid-labile organic phosphates. Anal Biochem 230:173-177

Du Jardin P, Rojas-Beltrán JA, Gebhardt C, Brasseur R (1995) Molecular cloning and characterization of a soluble inorganic pyrophosphatase in potato. Plant Physiol 109:853-860

Fernie AR, Roscher A, Ratcliffe RG, Kruger NJ (2001) Fructose 2,6-bisphosphate activates pyrophosphate:fructose-6-phophate 1-phosphotransferase and increases triose phosphate to hexose phosphate cycling in heterotrophic cells. Planta 212:250-263

Geigenberger P, Stitt M (1993) Sucrose synthase catalyses a readily reversible reaction in vivo in developing potato tuber and other plant tissues. Planta 189:329-339

Gibon Y, Blaesing OE, Hannemann J, Carillo P, Höhne M, Hendriks JHM, Palacios N, Cross J, Selbig J, Stitt M (2004) A robot-based platform to measure multiple enzyme activities in Arabidopsis using a set of cycling assays: comparison of changes of enzyme activities and transcript levels during diurnal cycles and in prolonged darkness. Plant Cell 16:3304-3325

Groenewald JH, Botha FC (2001) Down regulating pyrophosphatedependent phosphofructo-kinase (PFP) in sugarcane. Proc Int Soc Sugar Cane Technol 24:592-594

Groenewald JH, Botha FC (2008) Down-regulation of pyrophosphate: fructose 6-phosphate 1-phosphotransferase (PFP) activity in sugarcane enhances sucrose accumulation in immature internodes. Transgenic Res 17:85-92

Grof CPL, Campbell JA (2001) Sugarcane sucrose metabolism: scope for molecular manipulation. Aust J Plant Physiol 28:1-12

Hajirezaei M, Sonnewald U, Viola R, Carlisle S, Dennis D, Stitt M (1994) Transgenic potato plants with strongly decreased expression of pyrophosphate: fructose-6-phosphate phosphotransferase show no visible phenotype and only minor changes in metabolic fluxes in their tubers. Planta 192:16-30

Hatch MD, Sacher JA, Glasziou KT (1963) Sugar accumulation cycle in sugarcane. I. Studies on enzymes of the cycle. Plant Physiol 38:338-343

Hoepfner SW, Botha FC (2003) Expression of fructokinase isoforms in the sugarcane culm. Plant Physiol Biochem 41:741-747

Huber SC (1983) Role of sucrose-phosphate synthase in partitioning of carbon in leaves. Plant Physiol 71:818-821

Huber SC, Akazawa T (1986) A novel sucrose synthase pathway for sucrose degradation in cultured sycamore cells. Plant Physiol 81:1008-1013

Jang JC, Sheen J (1994) Sugar sensing in higher plants. Plant Cell 6:1665-1679
Jelitto T, Sonnewald U, Willmitzer L, Hajirezeai M, Stitt M (1992) Inorganic pyrophosphate content and metabolites in potato and tobacco plants expressing E. coli pyrophosphatase in their cytosol. Planta 188:238-244

Kalt-Torres W, Kerr PS, Huber SC (1987) Isolation and characterization of multiple forms of maize leaf sucrose-phosphate synthase. Physiol Plant 70:653-658

Kovács G, Sorvari S, Scott P, Toldi O (2006) Pyrophosphate:fructose 6-phosphate 1-phosphotransferase operates in net gluconeogenic direction in taproots of cold and drought stressed carrot plants. Acta Biol Szeged 50:25-30

Krook J, Van't Slot KAE, Vreugdenhil D, Dijkema C, Van Der Plas LHW (2000a) The triose-hexose phosphate cycle and the sucrose cycle in carrot (Daucus carota L.) cell suspensions are controlled by respiration and PPi:fructose-6-phosphate phosphotransferase. Plant Physiol 156:595-604

Krook J, Vreugdenhil D, Dijkema C, Van Der Plas LHW (2000b) Uptake of ${ }^{13} \mathrm{C}$-glucose by cell suspensions of carrot (Daucus carota) measured by in vivo NMR: cycling of triose-, pentoseand hexose-phosphates. Physiol Plant 108:125-133

Kruger NJ, Kombrink E, Beevers H (1983) Fructose 2,6-bisphosphate as a contaminant of commercially obtained fructose 6-phosphate: effect on PPi: fructose 6-phosphate phosphotransferase. Biochem Biophys Res Commun 117:37-42

Kulma A, Villadsen D, Campbell DG, Meek SEM, Harthill JE, Nielsen TM, MacKintosh C (2004) Phosphorylation and 14-3-3 binding of Arabidopsis 6-phosphofructo-2-kinase/fructose-2,6bisphosphatase. Plant J 37:654-667

Lang G, Michal G (1974) D-Glucose-6-phosphate and D-fructose-6phosphate. In: Bergmeyer HU (ed) Methods of enzymatic analysis, 3rd edn. Academic Press, New York, pp 1238-1242

Lingle SE, Smith RC (1991) Sucrose metabolism related to growth and ripening in sugarcane internodes. Crop Sci 31:172-177

MacKintosh C, Beattie KA, Klumpp S, Cohen P, Codd GA (1990) Cyanobacterial microcystin-LR is a potent and specific inhibitor of protein phosphatases 1 and $2 \mathrm{~A}$ from both mammals and higher plants. FEBS Lett 264:187-192

Maeshima M (2000) Vacuolar H(+)-pyrophosphatase. Biochim Biophys Acta 1465:37-51

Malone JG, Mittova V, Ratcliffe RG, Kruger NJ (2006) The response of carbohydrate metabolism in potato tubers to low temperature. Plant Cell Physiol 47:1309-1322

McCormick AJ, Cramer MD, Watt DA (2008) Differential expression of genes in the leaves of sugarcane in response to sugar accumulation. Trop Plant Biol 1:142-158

Michal G, Beutler HO (1974) D-Fructose-1,6-diphosphate, dihydroxyacetone phosphate and D-glyceraldehyde-3-phosphate. In: Bergmeyer HU (ed) Methods in enzymatic analysis, 3rd edn. Academic Press, New York, pp 1314-1319

Moore PH, Botha FC, Furbank RT, Grof CPL (1997) Potential for overcoming physio-biochemical limits to sucrose accumulation. In: Keating BA, Wilson JR (eds) Intensive sugarcane production: meeting the challenges beyond 2000. CAB International, Wallingford

Mustroph A, Albrecht G, Hajiresaei M, Grimm B, Biemelt S (2005) Low levels of pyrophosphate in transgenic potato plants expressing E. coli pyrophosphatase lead to decreased vitality under oxygen deficiency. Ann Bot 96:717-726

Nielsen TH, Stitt M (2001) Tobacco transformants with decreased expression of pyrophosphate:fructose-6-phosphate 1-phosphotransferase expression in the base of their sink leaves contain much higher levels of fructose-2,6-bisphosphate but only show minor changes in photosynthate partitioning. Planta 214:106116

Paul M, Sonnewald U, Hajirezaei M, Dennis D, Stitt M (1995) Transgenic tobacco plants with strongly decreased expression of 
pyrophosphate: fructose-6-phosphate phosphotransferase do not differ significantly from wild type in photosynthate partitioning, plant growth or their ability to cope with limiting phosphate, limiting nitrogen and suboptimal temperatures. Planta 196:277283

Reimholz R, Geigenberger P, Stitt M (1994) Sucrose phosphate synthase is regulated via metabolites and protein phosphorylation in potato tubers in a manner analogous to the photosynthetic enzyme. Planta 192:480-488

Roby C, Cortès S, Gromova M, Le Bail JL, Roberts JKM (2002) Sucrose cycling in heterotrophic plant cell metabolism: first step towards an experimental model. Mol Biol Rep 29:145-149

Roessner U, Wagner C, Kopka J, Tretheway RN, Willmitzer L (2000) Simultaneous analysis of metabolites in potato tubers by gas chromatography-mass spectrometry. Plant J 23:131-142

Roessner U, Willmitzer L, Fernie AR (2001) High-resolution metabolic phenotyping of genetically and environmentally diverse potato tuber systems. Identification of phenocopies. Plant Physiol 127:749-764

Rohwer JM, Botha FC (2001) Analysis of sucrose accumulation in the sugar cane culm on the basis of in vitro kinetic data. Biochem $\mathrm{J}$ 358:437-445

Rossouw D, Bosch S, Kossmann J, Botha FC, Groenewald JH (2007) Downregulation of neutral invertase activity in sugarcane cell suspension cultures leads to a reduction in respiration and growth and increase in sucrose accumulation. Funct Plant Biol 34:490 498

Sacher JA, Hatch MD, Glasziou KT (1963) Sugar accumulation cycle in sugar cane. III. Physical and metabolic aspects of cycle in immature storage tissues. Plant Physiol 38:348-354

Scott P, Kruger NJ (1994) Fructose 2,6-phosphatase levels in mature leaves of tobacco (Nicotiana tabacum) and potato (Solanum tuberosum). Planta 193:16-20

Siegl G, MacKintosh C, Stitt M (1990) Sucrose-phosphate synthase is dephosphorylated by protein phosphatase $2 \mathrm{~A}$ in spinach leaves. FEBS Lett 270:198-202
Stitt M (1990) Fructose 2,6-bisphosphate as a regulatory metabolite in plants. Annu Rev Plant Physiol 41:153-185

Stitt M (1998) Pyrophosphate as an alternative energy donor in the cytosol of plant cells: an enigmatic alternative to ATP. Bot Acta 111:167-175

Swart JC (2005) The characterization of vacuolar pyrophosphatase expression in sugarcane. Dissertation, University of Stellenbosch, South Africa

Theodorou ME, Plaxton WC (1996) Purification and characterization of pyrophosphate-dependent phosphofructokinase from phosphate-starved Brassica nigra suspension cells. Plant Physiol 112:343-351

Van Dillewijn C (1952) Botany of sugarcane. Cronica Botanica Co, Waltham

Viola R, Davies HV, Chudeck AR (1991) Pathways of starch and sucrose biosynthesis in developing tubers of potato (Solanum tuberosum L.) and seeds of faba bean (Vicia faba L.). Planta 183:202-208

Viola R, Davies HV, Sommerville LB (1994) A high performance liquid chromatographic method for the separation of hexose monophosphates and UDP glucose from plant extracts and its use to determine specific activities in radiotracer experiments. Phytochem Anal 5:10-14

Weiner H, Stitt H, Heldt HW (1987) Subcellular compartmentation of pyrophosphate and alkaline pyrophosphatase in leaves. Biochim Biophys Acta 893:13-21

Wendler R, Veith R, Dancer J, Stitt M, Komor E (1990) Sucrose storage in cell suspension cultures of Saccharum sp. (sugarcane) is regulated by a cycle of synthesis and degradation. Planta 183:31-39

Whittaker A, Botha FC (1997) Carbon partitioning during sucrose accumulation in sugarcane internodal tissue. Plant Physiol 115:1651-1659

Whittaker A, Botha FC (1999) Pyrophosphate: D-fructose-6-phosphate 1-phosphotransferase activity patterns in relation to sucrose storage across sugarcane varieties. Physiol Plant 107:379-386 